\title{
Safety climate research: taking stock and looking forward
}

\section{Sara J Singer, ${ }^{1}$ Timothy J Vogus ${ }^{2}$}

\begin{abstract}
${ }^{1}$ Assistant Professor of Health Care Management and Policy, Department of Healthcare Policy and Management, Harvard School of Public Health; Department of Medicine, Harvard Medical School; Mongan Institute of Health Policy, Massachusetts General Hospital, 677 Huntington Avenue, Boston, MA 02115 ${ }^{2}$ Assistant Professor of Management and Organization Studies, Vanderbilt Owen Graduate School of Management, $40121^{\text {st }}$ Avenue South, Nashville, TN 372032422
\end{abstract}

\section{Correspondence to} Sara J Singer; ssinger@hsph. harvard.edu

Received 5 October 2012 Revised 5 October 2012 Accepted 5 October 2012 Published Online First 29 October 2012

\section{SLinked}

- http://dx.doi.org/10.1136/ bmjqs-2011-000446 - http://dx.doi.org/10.1136/ bmjqs-2011-000582

To cite: Singer SJ, Vogus TJ. BMJ Qual Saf 2013;22:1-4.
Though long a subject of scholarly interest outside of healthcare, ${ }^{1}{ }^{2}$ attention to safety climate within healthcare began in earnest following the report by the Institute of Medicine: To Err is Human. Accomplishments of the growing body of literature on safety climate in healthcare include developing and validating a number of comprehensive measures of safety climate ${ }^{3-5}$; linking safety climate to a wide range of patient outcomes, such as patient safety indicators, ${ }^{6} 7$ rates of hospital readmission, ${ }^{8}$ and medication and other errors ${ }^{9}{ }^{10}$; and identifying leader and organisational practices that influence safety climate, such as Leadership WalkRounds ${ }^{11}$ and multifaceted interventions. ${ }^{12}$ This body of research has also impacted practice. For example, bolstered by a Joint Commission accreditation requirement, most hospitals now participate in regular efforts to survey and benchmark their safety climate. ${ }^{13}$

The two papers on safety climate in this issue represent additional contributions to this literature. ${ }^{1415}$ At the same time, they provide an opportunity to reflect on the nature of safety climate research, what scholars have already accomplished, and what additional research is needed now, in light of the chasm yet to be crossed. ${ }^{16} 17$ In this commentary, we describe what we see as the key contributions of these papers and use them as an occasion to take stock of the state of safety climate research. We then identify lingering conceptual and empirical challenges and suggest several strategies for resolving them and advancing the field.

The review of safety climate interventions by Morello and colleagues ${ }^{14}$ highlights that present enthusiasm for interventions outstrips the evidence supporting them. These authors found minimal effects from the interventions they studied. Moreover, very few studies examined interventions in comparison with a control group. These findings highlight two critical issues for researchers and practitioners. First, the authors note that, 'hospitals had underestimated the resource and organisational support required to make the patient safety initiatives work and achieve culture and practice change'. One implication is that delivery system interventions differ from clinical interventions in that they are context and implementation dependent. ${ }^{18-20}$

Implementing organisational interventions is not a matter of taking a pill or flipping a switch, and they must not be treated as such. That is, organisational interventions are not inherently effective or ineffective. They require attention to behavioural and relational implications of the change and sustained, dedicated commitment of personnel and other resources. In other words, context and implementation are essential to the success of any organisational intervention.

Second, although the safety climate literature would certainly benefit from more studies with rigorous research designs to adequately assess improvement, we argue that 'gold standard' evidence in health sciences (ie, randomised clinical trials) may not be as useful to organisational interventions. Organisational interventions are effective precisely because of their complex interactions with contextual and implementation factors. For this reason, stripping away context in a randomised field experiment to determine whether an intervention is effective may make studies less relevant to practitioners than information about why and under what conditions the intervention worked. Instead, we need to pursue more nuanced questions. What can the organisation do to increase the likelihood that the intervention will succeed? What mechanisms explain the effect of the intervention on safety climate?

Understanding the factors that are likely to undermine or inhibit the success of an 
intervention is also critically important. For example, existing evidence on the widely advocated Leadership WalkRounds suggests that perceptions of safety climate improve for individuals directly exposed to executives on rounds ${ }^{11}$ and with intensive programmes. ${ }^{21}$ These findings suggest important opportunities for better understanding how and when such interventions may influence safety climate. Specifically, what differentiates organisations that sustained Leadership WalkRounds from those that abandoned it? Why does the efficacy of rounds vary across units ostensibly implementing the same protocol? Under what conditions do the effects of rounds spill over to caregivers not directly exposed to them? In other words, in order to translate organisational research into practice requires a deeper understanding of the context in which the intervention occurred and how it affects those on the front line. A richer rendering of context and implementation may require quantitatively examining more complex relationships among an intervention and contextual factors (ie, interaction effects) or rigorous qualitative research, which Morello and colleagues found woefully lacking in the literature to date. ${ }^{14}$

A study of nurses and physicians in two Swiss and 10 US hospitals by Schwendimann and colleagues ${ }^{15}$ found that differences in safety climate were greater within hospitals than across hospitals or even across countries. This research builds on prior work which finds that safety climate rarely coheres at the organisational level and that there are significant differences within hospitals across hierarchical levels ${ }^{22-24}$ work areas $^{25} 26$ and professional disciplines. ${ }^{27-29}$ The findings by Schwendimann et $a l^{15}$ reaffirm the more general point that shared climates rarely emerge in organisations like hospitals without explicit and consistent effort to foster them. They are 'loosely coupled' organisations in that their constituent parts work fairly independently. ${ }^{30}$ Loose coupling is problematic for building an organisational safety climate in two ways. First, although healthcare units may operate largely independently, it is their combined product that determines a patient's care while hospitalised. Thus, it is the aggregation of unit-level subcultures that matters for patient safety. ${ }^{6}$ Second, adverse events often occur as a result of communication failures at the boundaries between unit, roles and hierarchical levels. $^{31}$ Ignoring the organisational level could obscure the most difficult problems that pose the greatest threat to patient safety. ${ }^{32}$ In other words, although Schweidmann and colleagues suggest that targeting interventions at the unit level is most appropriate, we need to balance this focus with organisation-level studies and interventions. For instance, future research could examine the effects of task interdependence (ie, coupling) on safety climate within and across units.

At the same time, studies of safety climate in healthcare should investigate the factors that affect agreement among employees about safety climate, that is, its strength ${ }^{33}$ and about dimensions of safety climate, that is, its profile ${ }^{34}$ as well as its level. We suspect that organisational and leader practices that give rise to a strong safety climate or learning-oriented profile within a unit can also help improve safety climate for the organisation as a whole.

The finding of unit-level differences in safety climate by Schwendimann et $a l^{15}$ suggests the importance of examining variation in unit manager behaviours and skills. Specifically, changing how managers interact with employees to make them more inclusive, that is, solicitous of their ideas, ${ }^{35}$ or more committed to their employees' welfare ${ }^{6}$ should improve leadermember exchange, that is, the quality of relationships between managers and subordinates, and, in turn, safety climate. ${ }^{37}$ Alternatively, studies might look at the effects of training managers in quality improvement or human factors on the level, strength and profile of safety climate in a unit and organisation. Whether leadership behaviours substitute for or enhance other practices influencing safety climate also merits empirical research.

In addition, we need studies that explore how the interventions that improve safety climate in one unit can be spread across units and come to characterise a hospital. Research is also needed to identify organisational mechanisms that foster a hospital-level safety climate. Prior studies of safety transformation highlight the important role of a visionary leader or leaders and the disciplined implementation of a specific protocol such as checklists for central line infections ${ }^{38}$ or method such as the Toyota Production System. ${ }^{39}$ These provide a good starting point for future research. Discovering mechanisms that enhance organisation and even system-wide safety climate will become increasingly important as developing Accountable Care Organisations in the USA requires better integration and safer care across the entire care continuum.

The paper by Schwendimann et al ${ }^{15}$ also identifies differences across dimensions of safety climate. This raises the question of whether safety climate is represented well by the proliferation of dimensions included in instruments measuring 'safety climate'. Originally safety climate referred to the extent to which an organisation or unit rewards, values, and supports safety ${ }^{1}$ and focused on how the leaders' patterns of interactions with frontline workers shape frontline perceptions and guides behaviour. ${ }^{40}$ Consequently, safety climate measurement focused on the attention paid to safety, relative priority given to safety over competing objectives, and safety information shared across the organisation. Subsequently, safety climate measures have expanded in ways that arguably dilute this domain, with dimensions like job demands and teamwork that could arguably be considered antecedents or outcomes rather than 
components of safety climate. ${ }^{4}$ In fact, safety climate first emerged as a corrective to the sprawling literature on organisational climate, which became irrelevant because it was so inclusive and failed to prune related, but distinct, constructs. ${ }^{41}$

Recognising this problem suggests two strategies for future research: (1) develop and test models that conceptually integrate the varying aspects of safety climate, and (2) test the complex interactions among components of safety climate. As an example of the former, Vogus and colleagues ${ }^{42} 43$ suggest that safety culture is a function of a set of interrelated and recursive processes of enabling (leader actions to emphasise safety), enacting (front line actions to surface and resolve threats to safety), and elaborating (systematically reflecting on and learning from performance). One recent study provides initial support for the enabling-enacting-elaborating model. ${ }^{44}$ Testing interactions among components of safety climate, like safety priority, safety procedures, and safety communication, and their effects on performance is an example of the latter. ${ }^{45} 46$

How safety climate surveys are deployed and the effects of utilising them also merit further research. Studies should examine the impact of administering safety climate surveys on safety climate. Research on social information processing suggests that what an organisation measures through employee surveys becomes socially validated and influences behaviour. ${ }^{47}$ Morello and colleagues ${ }^{14}$ corroborate this research when they suggest 'survey tool administration alone may have a positive impact on safety climate as it may increase staff awareness about positive culture and patient safety, enticing cultural change'. However, we also need detailed qualitative investigations of how organisations use safety climate surveys as a tool for learning and change as well as the conditions under which these surveys can catalyse change. Lastly, researchers could increase the impact of safety climate surveys by making them as parsimonious as possible. ${ }^{48} 48$ Shorter surveys would facilitate more widespread adoption and make them easier to interpret and act upon.

The two papers about safety climate in this issue provide the occasion to reassess and redirect research on safety climate. We recommend greater attention to organisational context and implementation of interventions, leader behaviours and practices, and qualitative and quantitative investigations of how and under what conditions unit level climates can spread throughout an organisation. We also suggest rethinking the scope of the safety climate construct. Returning to a narrower definition, integrating disparate elements of climate into theoretically grounded models, and more rigorous testing of interaction effects will avoid the diluting effects of over inclusiveness and facilitate the demonstration of important relationships and effects. Lastly, we suggest closer inspection of how the administration of safety climate surveys in practice itself improves safety climate. We believe that such an agenda will preserve safety climate as a vibrant area of research and will enhance its impact on theory and practice.

Competing interests None.

Provenance and peer review Not commissioned; internally peer reviewed.

\section{REFERENCES}

1 Zohar D. Safety climate in industrial organizations: theoretical and applied implications. J Appl Psychol 1980;65:96-102.

2 Helmreich R. Cockpit management attitudes. Hum Factors 1984;26:583-9.

3 Singla AK, Kitch BT, Weissman JS, et al. Assessing patient safety culture: a review and synthesis of the measurement tools. J Patient Saf 2006;2:105-15.

4 Flin R, Burns C, Mearns K, et al. Measuring safety climate in health care. Qual Saf Health Care 2006;15:109-15.

5 Colla J, Bracken A, Kinney L, et al. Measuring patient safety climate: a review of surveys. Qual Saf Health Care 2005;14:364-6.

6 Singer S, Lin S, Falwell A, et al. Relationship of safety climate and safety performance in hospitals. Health Serv Res 2009;44:399-421.

7 Mardon RE, Khanna K, Sorra J, et al. Exploring relationships between hospital patient safety culture and adverse events. J Patient Saf 2010;6:226-32.

8 Hansen L, Williams M, Singer S. Perceptions of hospital safety climate and incidence of readmission. Health Serv Res 2010;42:596-616.

9 Hofmann DA, Mark B. An investigation of the relationship between safety climate and medication errors as well as other nurse and patient outcomes. Personnel Psychol 2006;59:847-69.

10 Neal A, Griffin M. A study of the lagged relationships among safety climate, safety motivation, safety behavior, and accidents at the individual and group levels. J Appl Psychol 2006;91:946-53.

11 Thomas EJ, Sexton JB, Neilands TB, et al. The effect of executive walk rounds on nurse safety climate attitudes: a randomized trial of clinical units. BMC Health Serv Res 2005;5:28-36.

12 Pronovost PJ, Berenholtz SM, Goeschel CA, et al. Creating high reliability in health care organizations. Health Serv Res 2006;41(4 Pt 2):1599-617.

13 Sorra J, Famolaro T, Dyer N, et al. Hospital Survey on Patient Safety Culture: 2012 User Comparative Database Report (Prepared by Westat, Rockville, MD, under contract No. HHSA $290200710024 C)$. AHRQ Publication No. 12-0017. 2013.

14 Morello RT, Lowthian JA, Barker AL, et al. Strategies for improving patient safety culture in hospitals: a systematic review. BMJ Qual Saf 2012;XX:yy-yy.

15 Schwendimann R, Zimmermann N, Küng K, et al. Variation in safety culture dimensions within and between US and Swiss Hospital Units: an exploratory study. BMJ Qual Saf 2012;XX: yy-yy.

16 Wachter RM. Patient safety at ten: unmistakable progress, troubling gaps. Health Aff 2010;29:165-73. 
17 Leape L, Berwick D, Clancy C, et al. Transforming healthcare: a safety imperative. Qual Saf Health Care 2009;18:424-8.

18 Kaplan HC, Provost LP, Froehle CM, et al. The Model for Understanding Success in Quality (MUSIQ): building a theory of context in healthcare quality improvement. BMJ Qual Saf 2012;21:13-20.

19 Taylor SL, Dy S, Foy R, et al. What context features might be important determinants of the effectiveness of patient safety practice interventions? BMJ Qual Saf 2011;20:611-17.

20 Stevens DP, Shojania KG. Tell me about the context, and more. BMJ Qual Saf 2011;20:557-9.

21 Frankel A, Pratt Grillo S, Pittman M, et al. Revealing and resolving patient safety defects: the impact of leadership walkRounds on frontline caregiver assessments of patient safety. Health Serv Res 2008;43:2050-66.

22 Singer S, Falwell A, Gaba D, et al. Hospital patient safety climate: variation by management level. Med Care 2008;46:1149-56.

23 Hartmann C, Rosen A, Meterko M, et al. An overview of patient safety climate in the VA. Health Serv Rsch 2008;43:1263-84.

24 Pronovost PJ, Weast B, Holzmueller CG, et al. Evaluation of the culture of safety: survey of clinicians and managers in an academic medical center. Qual Saf Health Care 2003;12:405-10.

25 Campbell EG, Singer S, Kitch BT, et al. Patient safety climate in hospitals: act locally on variation across units. Jt Comm J Qual Patient Saf 2010;36:319-26.

26 Huang DT, Clermont G, Kong L, et al. Intensive care unit safety culture and outcomes: a US multicenter study. Int J Qual Health Care 2010;22:151-61.

27 Singer SJ, Gaba DM, Falwell A, et al. Patient safety climate in 92 US hospitals: differences by work area and discipline. Med Care 2009; 47:23-31.

28 Sexton JB, Thomas EJ, Helmreich RL. Error, stress, and teamwork in medicine and aviation: Cross sectional surveys. BMJ 2000;320:745-9.

29 Thomas E, Sexton J, Helmreich R. Discrepant attitudes about teamwork among critical care nurses and physicians. Crit Care Med 2003;31:956-9.

30 Weick KE. Educational organizations as loosely coupled systems. Adm Sci Q 1976;21(1):1-19.

31 Sutcliffe KM, Lewton E, Rosenthal MM. Communication failures: an insidious contributor to medical mishaps. Acad Med 2004;79:186-94.

32 The Joint Commission. Communication during patient hand-overs. Patient Safety Solutions 2007;1(3):1-4.

33 Schneider B, Salvaggio A, Subirats M. Climate strength: a new direction for climate research. J Appl Psychol 2002;87:220-9.
34 Weaver SJ. A configural approach to patient safety climate: the relationship between climate profile characteristics and patient safety. (Dissertation) Orlando FL: University of Central Florida, 2011.

35 Nembhard IM, Edmondson AC. Making it safe: the effects of leader inclusiveness and professional status on psychological safety and improvement efforts in health care teams. J Organiz Behav 2006;27:941-66.

36 Zohar D, Luria G. Climate as a social-cognitive construction of supervisory safety practices: scripts as proxy of behavior patterns. J Appl Psychol 2004;89:322.

37 Hofmann DA, Morgeson FP. Safety-related behavior as a social exchange: the role of perceived organizational support and leader-member exchange. J Appl Psychol 1999; $84: 286$.

38 Piotrowski MMM, Hinshaw DBD. The safety checklist program: creating a culture of safety in intensive care units. Jt Comm J Qual Improv 2002;28:306-15.

39 Kenney C. Transforming health care: Virginia Mason Medical Center's pursuit of the perfect patient experience. New York: Taylor \& Francis Group, 2009.

40 Zohar D. Modifying supervisory practices to improve subunit safety: a leadership-based intervention model. J Appl Psychol 2002;87:156-63.

41 Zohar D, Hofmann DA. Organizational culture and climate. In: Kozlowski SW, ed. Oxford handbook of industrial and organizational psychology. Vol 1. New York: Oxford University Press, 2012.

42 Vogus TJ, Sutcliffe KM, Weick KE. Doing no harm: enabling, enacting, and elaborating a culture of safety in health care. Acad Manag Perspect 2010;24:60-77.

43 Singer SJ, Vogus TJ. Reducing hospital errors: interventions that build safety culture. Ann Rev Public Health 2013.

44 Boyer KK, Gardner JW, Schweikhart S. Process quality improvement: an examination of general vs. outcome-specific climate and practices in hospitals. J Oper Manag 2012;30:325-39.

45 Naveh E, Katz-Navon T, Stern Z. Treatment errors in healthcare: a safety climate approach. Manag Sci 2005;51:948-60.

46 Katz-Navon T, Naveh E, Stern Z. Safety climate in healthcare organizations: a multidimensional approach. Acad Manag J 2005;48:1075-89.

47 Salancik GR, Pfeffer J. A social information processing approach to job attitudes and task design. Adm Sci Q 1978;23:224-53.

48 Meyer GS, Nelson EC, Pryor DB, et al. More quality measures versus measuring what matters: a call for balance and parsimony. BMJ Qual Saf 2012. 